\title{
Mitochondrial disease: Needs and problems of children, their parents and family. A systematic review and pilot study into the need for information of parents during the diagnostic phase
}

\author{
G. Noorda • M. Hermans-Peters • J. Smeitink • \\ T. van Achterberg $\cdot$ H. Kemps $\cdot$ W. Goverde • \\ L. Schoonhoven
}

Received: 9 July 2006 / Submitted in revised form: 6 February 2007 / Accepted: 14 February 2007 / Published online: 11 May 2007

(C) SSIEM and Springer 2007

\begin{abstract}
Summary Objective: Firstly, this paper aims to systematically review the mitochondrial disease literature to identify studies assessing the needs and problems in the daily life of children with a mitochondrial disease and of their parents and family. The second aim is to provide more insight into the need for information by the parents of these children during the diagnostic process while in hospital. Design: A systematic review and a pilot study, using a qualitative (focus group
\end{abstract}

\footnotetext{
Communicating editor: John Christodoulou

Competing interests: None declared

G. Noorda $(\bowtie) \cdot$ M. Hermans-Peters $\cdot$ W. Goverde

University Children's Hospital,

Radboud University Nijmegen Medical Centre,

432 CUKZ, P.O. Box 9101, 6500 HB Nijmegen,

The Netherlands

e-mail: G.Noorda@cukz.umcn.nl

J. Smeitink

Nijmegen Center for Mitochondrial Disorders,

Radboud University Nijmegen Medical Center,

Nijmegen, The Netherlands

T. van Achterberg $\cdot$ L. Schoonhoven

Center for Quality of Care Research,

Radboud University Nijmegen Medical Center,

Nijmegen, The Netherlands

\section{H. Kemps}

The HAN University of Arnhem \& Nijmegen,

Nijmegen, The Netherlands
}

\section{Electronic Supplementary Material}

The online version of this article (doi:10.1007/s10545-007-0426-0) contains supplementary material, which is available to authorized users. interviews; $n=7$ ) and a quantitative (questionnaire; $n=37)$ design. Results: Mothers reported great socioeconomic and psychoaffective strain and showed psychopathological symptoms in the two studies published with respect to this topic. The pilot study showed that parents considered an honest and interested attitude of the person who is giving the information as most important. Furthermore they wanted oral and written information and a central point where they could go with their questions at any time they felt the need. The need for information increased during the four phases of the diagnostic process and was highest in the fourth phase. Conclusions: The few studies found in the review, combined with expectations that having a mitochondrial disease must have a great impact on these children and their parents and family, call for more research in their needs and problems. Furthermore, there are gaps in the current information provision to parents of these children. A better understanding of the needs and problems of these children and their family is essential for effective care planning and might result in an improved quality of life.

Abbreviations
MD mitochondrial disease
PKU phenylketonuria

\section{Introduction}

The term mitochondrial disease is used for genetic diseases affecting cellular energy metabolism. Mito- 
chondria are the main energy-producing organelles of the cell, responsible for harvesting energy from nutrients. Defects in this process and the resulting deficiency in the energy-producing system disturb numerous cellular functions, especially in organs with high energy requirements such as the brain, muscles, heart, liver, kidneys, ears, eyes and the endocrine system (Smeitink et al 2001). Typical signs and symptoms include muscle weakness, hypotonia, vital sign instability, sensorimotor impairment, feeding and behavioural problems, developmental delays and sleep disturbances. These signs and symptoms are often exacerbated during periods of acute illness (Read and Calnan 2000).

The mitochondrial diseases vary considerably in their manifestations and in their effects on different organ systems, age at onset and rate of progression. This variation can complicate the identification of children with a mitochondrial disease. In general there are two types, those that manifest themselves at birth with rapid deterioration, often resulting in an early death, and those that manifest themselves later in life. Both types occur equally often. The mortality for the most severe forms of mitochondrial disease in childhood is up to $50 \%$ per year (Dodds 2001). Among the different groups of inborn errors of metabolism, mitochondrial diseases are the most frequent, with a current estimated incidence of at least 1 in 5000 live births (Smeitink et al 2006). Currently there is no effective treatment. Treatment is limited to supplemental and supportive interventions such as dietary modifications, nutritional supplement, pharmacological agents and exercise therapy, of which the effectiveness varies from patient to patient. There is currently no clear evidence supporting the use of these interventions (Chinnery et al 2006). The purpose of therapy is to maximize normal function, alleviate symptoms and delay the progression of illness (Dodds 2001). Possible treatments such as enzyme- or gene therapy are not yet feasible (Smeitink et al 2006).

In recent years, substantial progress has been made in the clinical and biochemical understanding of mitochondrial diseases. However, a systematic review of the literature on the needs and problems of children with a mitochondrial disease and their family is lacking. More insight into, and better understanding of, these needs and problems are essential for good-quality care planning, resulting in improved quality of life.

In preparation for a major study into the needs and problems of children with a mitochondrial disease and their parents and family, we carried out a systematic review and a pilot study. The review aims to identify all types of needs and problems of children with a mitochon- drial disease and their parents and family in daily life, as described in the literature. From practice and from interviews with parents (Janssen and Bruijstens 2001), we know that parents experience many deficiencies in the information received during the diagnostic process in practice in our institution. Identifying their need for information during this period in the University Children's Hospital of the Radboud University Nijmegen Medical Centre Nijmegen, is therefore the second aim of the study, which serves as a pilot for the feasibility of the major study mentioned.

\section{Methods}

Part I. The systematic literature review

\section{Search strategy}

A systematic review of the literature was conducted using searches in PubMed (1965-2005), CINAHL (1982-2005), PsychInfo (1982-2005) and all databases of the Cochrane Library (up to 2005). Search terms used to describe 'children, parents and family', 'problems and needs', and 'mitochondrial diseases' were selected using the thesaurus function of the databases and free text if the thesaurus did not contain the term (Supplementary Table 1).

The selected search terms for 'children, parents and family', and for 'problems and needs' were combined within the groups using the Boolean operator 'OR'. These two searches were then combined using the Boolean operator 'AND'. Subsequently, this search was combined with 'mitochondrial disease' (using the Boolean operator 'AND'). In addition, a manual search of the reference lists of the articles found for the review was conducted to retrieve important studies not recovered using the search terms.

\section{Selection criteria}

The abstracts of retrieved studies were independently assessed for inclusion by two reviewers (L.S. and G.N.). To be included in the review, the retrieved articles had to be a report of research focused on children (0-18 years) with a mitochondrial disease, their parents and/or family, describing problems and needs and published in a peer-reviewed journal. Clinical and biochemical studies, studies focusing on adult patients only and case-reports were excluded. Disagreement between reviewers on inclusion was resolved through discussion of the study in the 
light of the inclusion criteria described. There were no abstracts for which consensus could not be achieved.

Part II. The pilot study: need for information

\section{Design of the study}

For the pilot study we used a descriptive design consisting of a qualitative and a quantitative part. Focus group interviews were used to obtain a topic list for a retrospective systematic inventory of the need for information by the parents.

\section{Population}

The participants in this study were parents of children who underwent a skeletal muscle biopsy in 2002 and 2003 at the University Children's Hospital of the Radboud University Nijmegen Medical Centre ( $n=65$ children).

Parents of 38 children met the inclusion and exclusion criteria: they went through the diagnostic process at this hospital, they lived in the Netherlands, and their child was $0-10$ years of age and had been diagnosed with a mitochondrial disease. The parents of 27 children were excluded because they did not meet the inclusion criteria. We also excluded parents of four children who died because we suspected the perception of the need for information of these parents could possibly be biased by the death of their child.

Focus group interviews

Two focus group interviews were performed with the parents who had a child with a mitochondrial disease in order to obtain in-depth information about their need for information.

\section{Selection of respondents}

We aimed for at least four parents per focus group. Names of 16 children were randomly selected from the list by pulling names from a hat (Polit and Beck 2004). A letter, describing the objective of the study and an invitation to participate, was sent to their parents. After one week, the nurse-practitioner (MH-P) called the parents to confirm or cancel their participation.

\section{Data-collection}

Data were collected during the two focus group interviews at our hospital on two different days in May 2005.
Each interview took about two hours. A semi-open format was chosen (Krueger and Casey 2000). Parents were invited to talk about their experiences and questions concerning the information they needed, had received or may have missed. Regarding the information, parents were asked to discuss the content, the way in which information was given, and the timing of the information. Timing was specified according to the four phases of the diagnostic process:

Phase 1: The period commencing as soon as the child had been referred to a paediatrician specializing in metabolic diseases, including the first visit to the outpatient clinic or during an acute episode of illness requiring hospitalization.

Phase 2: The period including medical examination, clinical or outpatient, and giving information about the results of the examinations at the outpatient clinic or the medical examination during the acute illness.

Phase 3: The period, possibly occurring during a hospitalization, including the muscle biopsy.

Phase 4: The period commencing after the muscle biopsy has been performed and until the diagnosis is known.

The results of the first interview were used for the second interview, to obtain more detailed information about statements. During the interviews the nursepractitioner kept notes of observations of nonverbal behaviour and the most important statements. Tape recordings were also made at both interviews.

\section{Data analysis}

Both interviews were typed out in full. The text was independently assessed by the nurse-practitioner and two nursing researchers. Non-relevant text was deleted and saved in another file. Relevant text fragments were arranged into labels and subsequently grouped under a central label (Baarda et al 1995; Hutchinson 1993).

\section{Reliability and validity}

To increase reliability and internal validity we used techniques that secure credible findings and interpretations (Lincoln and Guba 1985): To check the data obtained, the process of analysis was carried out independently by the nurse-practitioner and two nursing researchers (peer debriefing). They compared the findings of data analysis with raw data and notes, observations, interpretations and ideas from the nursepractitioner written in the logbook (referential 
adequacy) (Baarda et al 1995; Hutchinson 1993; Lincoln and Guba 1985).

Differences and disagreement between the three persons involved were resolved through discussion. The positive feedback of the parents contributed to the validity of the data obtained. The member check, whereby notes and interpretations of the nurse-practitioner were summarized during and at the end of the interview and the parents were asked to confirm the accuracy of the most important conclusions, was used as the most important technique (Lincoln and Guba 1985).

The questionnaire

The results from the focus group interviews were the basis for the written closed-format questionnaire. The content of the labels was transformed to 36 propositions as described in the Supplementary Table 2. Each proposition had four categories to answer: totally disagree, disagree, agree and totally agree (Likertscale 1-4). Parents were asked to value each proposition for each phase of the diagnostic process.

\section{Data collection}

The questionnaire was sent to both parents of all the 38 children ( $n=76$ parents). A letter with a description of the objective of the study and an invitation to answer the questions anonymously was added to the questionnaire. After two weeks the nurse-practitioner called the parents to remind them of their participation.

\section{Data analysis}

Owing to the small number of participants in this pilot study, the four response categories were compressed into two: the categories disagree and totally disagree were compressed into 'disagree' and the categories agree and totally agree were compressed into 'agree'. The positive scores were presented using percentages.

\section{Reliability and validity}

To increase reliability and face validity, the questionnaire was assessed by a nursing researcher, the head nurse of the metabolic diseases ward, the medical chief of the department of mitochondrial diseases, and a parent of a child with a mitochondrial disease who is also the chairman of the association of children with a mitochondrial disease. The list was assessed on clarity, superfluousness, completeness, design and whether the questions addressed the aim of this study. This resulted in a questionnaire that all involved persons agreed with.

\section{Results}

Part I. Results of the systematic literature review

The search of the PubMed, CINAHL and PsychInfo databases and the Cochrane Library resulted in a total of 722 studies; after adjusting for duplicates, 717 remained. Of these, 714 were excluded because they had no abstract $(n=160)$, were clinical or biochemical $(n=548)$, did not concern children with a mitochondrial disease or their parents or family $(n=1)$ or were nonsystematic reviews, case reports, letters or tutorials $(n=5)$. The full text of the remaining three studies was examined in more detail. One did not meet the inclusion criteria because it had an unclear description of the population. Two studies were included (Read 2003; Varvogli and Waisbren 1999). Table 1 gives information about their characteristics and results. The manual search of the reference lists of the articles found for the review did not provide additional studies.

\section{Needs and problems of parents of children with a mitochondrial disease}

We found no study describing the needs and problems of children with a mitochondrial disease. The included studies described psychosocial needs or problems of the mothers only. In the study by Varvogli and Waisbren (1999), 56\% of the mothers $(n=34)$ had extreme scores in the pathological range on three scales of the Minnesota Multiphasic Personality Inventory, second edition: hypochondriasis $(55 \%)$, hysteria $(62 \%)$ and paranoia $(62 \%)$. For these mothers, more than $50 \%$ of the children were reported to have more than four special needs, such as wheelchair dependence, developmental delays, gastrointestinal tube feeding and vision problems.

Read (2003) found that mothers of children with a mitochondrial disease $(n=29)$ had more socioeconomic and psychoaffective strain in many aspects of life than mothers of children with the non-mitochondrial metabolic disease phenylketonuria (PKU) $(n=29)$. According to their mothers, children with a mitochondrial disease (MD) developed impairments in communication, daily living skills, socialization and motor skills. These children also required a significantly larger number of healthcare services than children 
Table 1 Description and results of the systematic review

\begin{tabular}{|c|c|c|}
\hline & Varvogli and Waisbren (1999) & Read (2003) \\
\hline Design & $\begin{array}{l}\text { Quantitative } \\
\text { Comparative }\end{array}$ & $\begin{array}{l}\text { Quantitative } \\
\text { Descriptive } \\
\text { Comparative }\end{array}$ \\
\hline$N$ (persons) & 42 & 58 \\
\hline $\begin{array}{l}\text { Subject group and } \\
\text { underlying disease }\end{array}$ & $\begin{array}{l}\text { Mothers of } 50 \text { children with MD } \\
\text { (40 biological and } 2 \text { adoptive) } \\
\text { followed by the Mitochondrial } \\
\text { Clinic at Children's Hospital in } \\
\text { Boston }\end{array}$ & $\begin{array}{l}\text { Mothers of children with MD } \\
(n=29) \\
\text { Mothers of children with PKU } \\
(n=29)\end{array}$ \\
\hline Country & USA & USA \\
\hline Focus aim & $\begin{array}{l}\text { To describe whether there is } \\
\text { psychopathology associated } \\
\text { with mothering these } \\
\text { chronically ill children. If so, is } \\
\text { there a typical pattern of } \\
\text { psychopathology? }\end{array}$ & $\begin{array}{l}\text { To describe the socioeconomic } \\
\text { and psychoaffective strain on } \\
\text { the mother and the health } \\
\text { services required to care for a } \\
\text { child with a biochemical } \\
\text { genetic disorder and } \\
\text { to compare those factors } \\
\text { in families with PKU and } \\
\text { mitochondrial disease. }\end{array}$ \\
\hline Measurement & Telephone interview & Telephone interview \\
\hline Instruments & $\begin{array}{l}\text { Questionnaire based on the } \\
\text { Minnesota Multiphasic } \\
\text { Personality Inventory, second } \\
\text { edition (MMPI-2) }\end{array}$ & $\begin{array}{l}\text { Vineland Adaptive Behavior } \\
\text { (VAB) Scale, } 1984 \\
\text { Parenting Stress Index, } 1995\end{array}$ \\
\hline \multirow[t]{2}{*}{ Quality of studies } & $\begin{array}{l}\text { Not specified in this publication. } \\
\text { MMPI-2 is a revision of the } \\
\text { classic multiple-choice } \\
\text { questionnaire that is used } \\
\text { extensively in research as a } \\
\text { measure of personality and } \\
\text { psychopathology. }\end{array}$ & $\begin{array}{l}\text { VAB-scale: Conform the author } \\
\text { studies confirming to the } \\
\text { internal consistency, test-retest } \\
\text { and inter-rater reliability as well } \\
\text { as evidence of construct, content } \\
\text { and criterion-validity that are } \\
\text { well documented in the test } \\
\text { manual. Parenting stress index, short form. } \\
\text { Test-retest reliability } 0.84 \alpha \text {-reliability } 0.91 \text {. } \\
\text { Conform the author numerous studies } \\
\text { documented construct and predictive } \\
\text { validity in the test manual. }\end{array}$ \\
\hline & $\begin{array}{l}\text { Selection of population is } \\
\text { unclear. }\end{array}$ & $\begin{array}{l}\text { Selection of population is } \\
\text { unclear. }\end{array}$ \\
\hline $\begin{array}{l}\text { Results: } \\
\text { Needs and problems }\end{array}$ & $\begin{array}{l}34 \text { of the } 42 \text { mothers had scores } \\
\text { in the pathological range on } \\
\text { three or more scales, most } \\
\text { hypochondriasis, hysteria and } \\
\text { paranoia scales. }\end{array}$ & $\begin{array}{l}\text { Mothers of children with MD } \\
\text { report significantly greater } \\
\text { socioeconomic and } \\
\text { psychoaffective strain and } \\
\text { require more healthcare } \\
\text { resources than do mothers of } \\
\text { children with PKU. }\end{array}$ \\
\hline
\end{tabular}

with PKU; a greater involvement of specialists (three or more specialists, MD 55\%/PKU $0 \% ; p<0.0001)$ and more hospitalizations since birth (four or more times, MD 72\%/PKU 7\%; $<<0.0001)$. Children with mitochondrial disease also required a lot of healthcare resources, such as gastronomy tubes, wheelchairs, physical therapy, speech therapy and homecare nursing, whereas these services were not often used by children with PKU. Finally, mitochondrial disease caused significantly more strain on many aspects of these mothers' lives than on the lives of mothers of a child with PKU, e.g. more health-related expenses for 
the child and a higher number of days of missed work. They also reported a greater worry about the child's health and future, less satisfaction with their social support network and higher scores on the Parent Stress Index. According to the mothers, the impact on all aspects of the child's development was large.

Part II. The pilot study

\section{The respondents}

Ten parents of 8 children (of the 32 approached parents of 16 children) accepted the invitation to participate in a focus group. The most important reasons for rejecting the invitation were the time to travel to our centre (12 parents of 6 children), unavailability due to their schedule ( 5 parents of 5 children), and issues in family life, such as recent death of a family member (2 parents of one child). Finally, 3 of the 10 parents did not attend owing to a sickness of a child or gave no reason. A total of 7 parents of 5 children participated in the interviews, 5 women and 2 men. They all had Dutch nationality and a mean age of 37.3 years (range 25-44 years).

Of the 76 parents 37 returned the questionnaire. They all had Dutch nationality and a mean age of 35.4 years (range 25-51 years).

\section{The need for information of parents with a suspected mitochondrial disease during the diagnostic period}

The central labels from the focus group interviews addressed the content of information, the source of information, the attitude and availability of the information provider and the context in which the information is given. The results from the questionnaire are grouped according to these labels. Supplementary Table 2 gives more specific information about the combined results.

The content of information. Parents felt that getting information about where they could go with their questions and having a focal point for their questions was most important. Information on symptoms, prognosis and the consequences for their child and family was also important. Information about spiritual support, support with childrearing and regional differences in treatment were the least important in the diagnostic process.

The need for information on many items, e.g. about the risk of early death, life expectancy, the state of the art in medical science, alternative medicine and heredity increased with each phase and was greatest in the fourth phase. More than half of the respondents thought information about the symptoms of the disease was important in all phases of the diagnostic process.

The source of information. Parents mostly preferred written information and leaflets in all four phases of the diagnostic process. Information about effectively searching the Internet was also important to them. The possibility of asking professionals questions by e-mail was considered least important, but seemed more important in the fourth phase. Some parents mentioned personal communication as equally important.

The attitude and availability of the information provider. Parents considered the attitude and availability of the information provider as the most important items of all. They needed this person to be honest, interested and equally honest when he or she also does not really know what to do. Parents also thought it very important that there should be facilities where they could go with their questions at any time. This all applied to all four phases of the diagnostic process.

Aspects of the context in which the information is given. Parents felt that the development of the disease process and the coping phase, the presence of support, the management of care and personal factors influenced their information processing. In the diagnostic phase they felt that it was important to receive information about the acceptance of the disease and how to fit this into daily life. Less important were receiving support in bringing up their child and exchanging experiences with other parents.

\section{Discussion}

Main results

The review aimed to identify needs and problems of children with a mitochondrial disease and their parents and family. It resulted in only two studies on needs and problems of the mothers only (Read 2003; Varvogli and Waisbren 1999), from which it was hardly possible to identify needs and problems of this group. It showed that mothers experience great socioeconomic and psychoeffective problems and have psychopathological symptoms (Read 2003; Varvogli and Waisbren 1999). The pilot study aimed to identify the needs for 
information of parents during the diagnostic process. Parents considered the attitude and availability of the information provider as the most important. The need for information increased over the four phases of the diagnostic process and was highest during the fourth phase.

\section{Limitations}

The systematic review was conducted rigorously and provides a balanced assessment of the current evidence. Nevertheless it has its limitations. Assessments of abstracts, instead of full-text articles, may be disputable if the given information is limited. Another limitation is that we did not systematically review the grey literature.

In the pilot study, the focus groups were small and the questionnaire was not tested for its reliability and validity. The results should therefore be interpreted with caution. The results cannot automatically be generalized to the parents of children in other institutions' children's departments treating mitochondrial diseases. The study was retrospective, the diagnostic process took place more than one to two years ago. The perception of this period could have been changed over time. The parents of children with suspected but not diagnosed mitochondrial disease were not included in the study. They may have perceived this period differently. Also, the children themselves were excluded and therefore we do not have data about their experiences and perception. The problems and needs of the parents and children probably differ depending on the developmental phase of the child or disease characteristics, e.g. neurological and non-neurological. Unfortunately, the small numbers in our study do not allow us to investigate this hypothesis. In a larger study the problems and needs should be studied in the different subgroups, i.e. 0-2, 2-5 and 5-10years of age, and with different disease characteristics. Finally, the pilot study was carried out during a period in which the children were still in follow-up care or treatment by a metabolic paediatrician of the University Children's Hospital of the Radboud University Nijmegen Medical Centre. This may have resulted in socially desirable answers.

\section{Conclusions}

In spite of the limitations of our study it has some relevance. Even with the limited number of studies found, we suspect that the impact on daily life might be large for the children as well as for their parents and family. The study of Read (2003), indicating that these children have more impairments and require more health care services than children with a nonmitochondrial metabolic disease (phenylketonuria), supports this assumption. Also, from studies in children with other chronic diseases, we know that adaptation to medical treatments and limitations in daily life are important problems for children during their whole life, just as is coping with emotion and stress (Tielen 2003).

Parents of chronically ill children have a need for normality, certainty, information and partnership (Fisher 2001). Kars and colleagues (2005) described the conflicting wishes and needs of parents: to have optimal health for their child on the one hand and to have a normal life for them on the other. This implies a complex way of life for parents of children with a chronic disease (Kars et al 2005).

In our pilot study we focused on one of the needs of parents, namely their need for information. We gained insight into their needs and can conclude that there are gaps in the giving of information. We expect that filling these gaps would result in a better quality of life. Parents in this study considered their need for an honest, interested and available professional who is providing the information as most important. They prefer a good 'match' with the professional. Next, parents reported their need for a focal point where they can go with their questions as important. Also, Van der Zwaard and colleagues (2003) described the availability of professionals as a deciding factor for satisfying patients' need for information. Parents need information during all the four phases of the diagnostic process, but especially in the fourth phase. This conclusion was supported by Nelissen and colleagues (1999), who reported that patients need the most information during the periods in which they are told the results of an examination or treatment. This is probably due to the approaching diagnosis and increasing uncertainty about the future.

Finally, we suspect that the impact on daily life might be large for the family of children with a mitochondrial disease. Houtzager (2004) described in her literature study emotional, sociobehavioural, physical and positive reactions of siblings to their brother/ sister with cancer. She also reported that they were most affected by the illness of their brother/sister in the first months and experienced a more serious burden from the illness than is perceived by their parents. Physical and emotional problems remained mostly unnoticed, although distressed parents were more focused on the child's physical health (Houtzager 2004). 


\section{Challenges for the future}

The gap between the increasing number of clinical and biochemical studies of mitochondrial diseases and studies of needs and problems of children with this disease, their parents and family point out a considerable lack of research. This lack of research, the increase of the incidence of mitochondrial diseases in childhood and the expectations of having this disease that bring many needs and problems and have a large impact on the child as well as its parents and family, calls for more high-quality studies in this domain.

In our pilot study we focused on the need for information only of parents. Professionals can play an important role in improving the provision of information by filling the gaps with respect to the need the parents have during the diagnostic process; for example, by developing a procedure for structured information giving.

Information is only one part of the needs and problems of children with a mitochondrial disease and their parents and family. Further research is necessary to provide more insight into their whole world, and especially into their needs and problems. A first step is to assess physical, psychological, social and spiritual needs and problems of children, their parents and family, in the different stages of the child's development and the different stages of the disease. Large multicentre studies are needed to improve the quality of care and subsequently the quality of life of these children and their family.

Acknowledgement The study was financed by the University Children's Hospital of the University Medical Centre Nijmegen. We thank the members of the Workgroup Evidence Based Practice (WEBP), especially Jacqueline Theunissen, MScN, RN, for their contribution to this study.

Addendum The reader can request an overview of the search strategy and/or an overview of the results of this study by sending an e-mail to G.Noorda@cukz.umcn.nl.

\section{References}

Baarda DB, de Goede MPM, Teunissen J (1995) Basisboek kwalitatief onderzoek [Basic book Qualitative Research]. Leiden: Stenfert Kroese.
Chinnery P, Majamaa K, Turnbull D, Thorburn D (2006) Treatment for mitochondrial disorders. The Cochrane Collaboration. Chichester: Wiley.

Dodds MG Analysis of Mitochondrial Metabolic Defects, 15-112001.

Fisher HR (2001) The needs of parents with chronically sick children: a literature review. J Adv Nurs 36(4): 600-607.

Houtzager BA (2004) Siblings of pediatric cancer patients. Dissertation. University of Amsterdam.

Hutchinson S (1993) Grounded theory: the method. In: Munhall P, Oiler Boyd C, eds. Nursing Research, A Qualitative Perspective. New York: National League for Nursing Press, 180-212.

Janssen A, Bruijstens J (2001) Ketenkwaliteit in het zorgtraject van kinderen met methylmalonacedemie [The quality of integrated care of children with a methylmalonacidaemia]. Unpublished Paper, available from the author.

Kars M, Duijnstee M, Grypdonck M (2005) Leren laveren, het begeleiden van ouders van zieke kinderen met een chronische ziekte: een handreiking voor verpleegkundigen [Learn to steer a middle course, supporting parents of sick children with a chronic disease: a helping hand for nurses]. Maarssen: Elsevier Gezondheidszorg.

Krueger R, Casey MA (2000) Focus Groups, a Practical Guide for Applied Research. Newbury Park: Sage publications.

Lincoln Y, Guba G (1985) Naturalistic Inquiry. Newbury Park: Sage Publications.

Nelissen P, Eden D van, Maas S (1999) The quality of information services to cancer patients in the hospital: an explorative study. Electron J Commun 9: 1-3.

Polit DF, Beck CT (2004) Nursing Research: Principles and Methods. Philadelphia: Lippincott Williams and Wilkins.

Read CY (2003) The demands of biochemical genetic disorders: a survey of mothers of children with mitochondrial disease or phenylketonuria. J Pediatr Nurs 18: 181-186.

Read CY, Calnan RJ (2000) Mitochondrial disease: beyond etiology unknown. J Pediatr Nurs 15: 232-241.

Smeitink JA, Heuvel L van den, DiMauro S (2001) The genetics and pathology of oxidative phosphorylation. Nat Rev Genet 2: 342-352.

Smeitink JA, Zeviani M, Turnbull DM, Jacobs HT (2006) Mitochondrial medicine: a metabolic perspective on the pathology of oxidative phosphorylation disorders. Cell Metab 3: 9-13.

Tielen L (2003) Een studie naar de bijdrage van ICT-voorzieningen aan de kwaliteit van leven van kinderen en jongeren met chronische ziekten [A study to the contributionf of ICT-facilities on the quality of life of children and adolescents with a chronic disease]. VSB-fonds, Stichting Nederland Kennisland.

van der Zwaard J, Francke A, Gamel C (2003) Informatiebehoeften van patienten die palliatieve zorg ontvangen en hun naasten [The need for information of patients receiving palliative care and their relatives]. Verpleegkunde 1: 8-20.

Varvogli L, Waisbren SE (1999) Personality profiles of mothers of children with mitochondrial disorders. J Inherit Metab Dis 22: 615-622. 